\title{
Re-establishment of visual circuitry after optic nerve regeneration
}

\section{Summary}

In mammals there are a few circumstances in which axotomised ganglion cell axons can regenerate. For instance, in vitro explants of retina can be encouraged to regenerate axons into appropriate culture media. ${ }^{1}$ Similarly, axotomised ganglion cells can regenerate into a peripheral nerve graft surgically connected to the optic nerve head, ${ }^{2}$ and during early development axons are able to regenerate across the retina to re-enter the optic nerve. ${ }^{3}$ This is certainly encouraging, but we are a long way from applying these observations to clinical practice. We need to know whether regenerating axons also retain a functional capacity for navigation. We must ask whether a regenerated projection is likely to be topographic rather than disordered. In this brief review we will look at some selected models of ganglion cell regeneration in order to examine this question of navigation in more detail. This is an important issue: the capacity to re-establish appropriate rather than random connections after ganglion cell regeneration would most likely be necessary for any meaningful return of visual function.

Key words Optic nerve, Peripheral nerve graft, Rat, Retina, Specificity

In any successful model of regeneration, a lesioned neuron must have the capacity both to survive the effects of axotomy and to re-extend an axon within the central nervous system (CNS). Lesioned mammalian ganglion cells can regenerate from retinal explants in tissue culture, ${ }^{1}$ where the ganglion cells are bathed in favourable culture media and can be separated from natural inhibitory molecules, such as those associated with oligodendrocytes. ${ }^{4}$ In vivo, regeneration is harder to achieve, but nevertheless may occur in the presence of exogenous intravitreal growth factors ${ }^{5}$ and/or peripheral nerve grafts which provide a favourable conduit for regenerating axons. ${ }^{6,7}$ Ganglion cell regeneration may occur spontaneously without these complex manipulations, but only at very early ontogenetic stages (the reader is referred elsewhere for a general review of this topic ${ }^{3}$ ).

If ganglion cell regeneration is indeed possible, how might regenerating axons terminate and interact with target neurons? Kierstead and colleagues ${ }^{8}$ have shown that visually evoked potentials are recordable in layers 2 and 3 of the superior colliculus after ganglion cell regeneration through peripheral nerve grafts connected to the tectum in hamsters. This is strong evidence that in addition to axonal regeneration, lesioned ganglion cells are also able to re-establish functional synapses. Behavioural responses mediated by a regenerated projection are more difficult to demonstrate, but there is evidence that peripheral-nerve-grafted rats may be able to navigate using basic visual cues ${ }^{9}$ and that light-dark conditioning is possible in grafted hamsters. ${ }^{10}$ If valid, these behavioural experiments certainly suggest that the regenerating functional synapses may also be able to re-establish further connections with higher centres.

There is therefore reasonable evidence not only that ganglion cells can regenerate but also that functional connections may reform with target neurons. Could this re-establishment of visual circuitry following optic nerve regeneration be a fortuitous but random result, or is it the result of active mechanisms of axon guidance? This is a difficult but important question, encompassing a vast topic of molecular mechanisms of axon growth and important studies in non-mammalian vertebrates. In this review we shall concentrate on morphological observations from selected mammalian experiments and look carefully for evidence that regenerating ganglion cells might also navigate and thereby re-establish topographic projections.

\section{Ganglion cell regeneration early in development}

The immature visual system of mammals has many characteristics that make it far more conducive to axon regeneration than the adult.
Robert E. MacLaren Oxford Eye Hospital Walton Street Oxford OX2 6AW, UK

Tel: $+44(0) 1865276397$ Fax: $+44(0) 1865276361$

Presented at the 1998 Oxford Ophthalmological Congress

Received: 27 July 1998 Accepted in revised form: 8 March 1999 
Growth cones are normally repelled by myelin proteins associated with oligodendrocytes ${ }^{4}$ and thus at early stages (prior to myelination) this inhibitory influence can largely be discounted. ${ }^{11,12}$ Similarly, astrocytes in the mature CNS react to injury by creating a glial scar, which acts a physical barrier and may further produce other inhibitory molecules (for example, chondroitin sulphate) which may further impede regeneration: this glial reaction is much less marked early in development. ${ }^{13,14}$ Moreover, developmentally regulated growth factors or neurotrophins may also be in abundance at early stages, both within the retina and at tectal targets, to sustain and encourage regeneration of lesioned axons. ${ }^{15-17}$ In theory, therefore, the CNS environment in the immature mammal is more conducive for regeneration than in the adult, and navigational interactions are already taking place to guide axons during development. This is thus a most favourable model in which to look for navigation during regeneration.

The retinofugal pathway develops prenatally in rodents, making regeneration studies technically difficult to perform. The opossum, however, is a mammal in which the retinofugal pathway develops after birth (in a pouch rather than a uterus). ${ }^{18}$ In the Monodelphis opossum, we previously demonstrated that ganglion cells regenerate across a surgical transection of the nerve fibre layer made up to the twelfth postnatal day (P12). ${ }^{19}$ By using tritiated thymidine labelling to birthdate ganglion cells, we can deduce which axons are lesioned at the time of surgery and therefore differentiate the regenerating axons from those that are growing out 'de novo' as part of the normal process of development. After retrogradely labelling ganglion cells from the optic nerve or tract, detailed analysis of regenerating axons can be made by examination of the flattened retina around the lesion site. ${ }^{20}$ Thus we found that mammalian ganglion cells do have a capacity to regenerate within this unique period early in development. But how might these regenerating axons navigate across the retina?

\section{Axon guidance in the retina}

Experiments with embryonic avian retinal explants have shown that ganglion cell growth cones are directed during development towards the optic disc along a trophic gradient operating from peripheral to central retina. ${ }^{21}$ In the opossum, the growth of regenerating ganglion cell axons arising from the lesioned segiment of retina is unequivocally centripetal (Fig. 1). Thus creating a lesion across the retina does not appear significantly to disrupt this gradient. Silver and colleagues ${ }^{22,23}$ have suggested that chondroitin sulphate may also be an important 'gradient' molecule for retinal development. This molecule shows properties of growth cone repulsion (as discussed above, it is also expressed by proliferating astrocytes around sites of adult CNS injury). ${ }^{13,24}$ The retina is slightly different from the CNS, however, in that there are few astrocytes and injury does not result in a significant re-expression of chondroitin sulphate. ${ }^{14}$ This may partly explain why regenerating axons can also
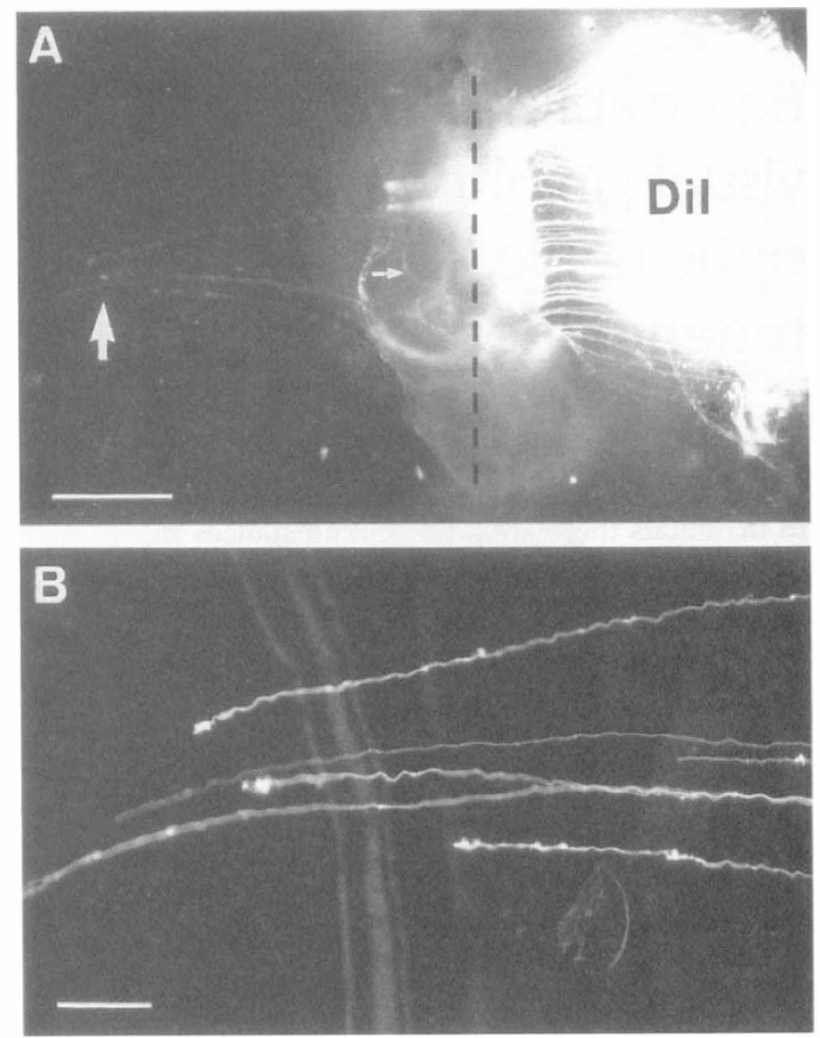

Fig. 1. Flat-mounted retina of a postnatal day 11 (P11) opossum fixed in $4 \%$ paraformaldehyde. The lesion was made at $P 7$, allowing for 4 days for regeneration. (A) Axons (labelled with DiI tracer) can be seen emerging from the lesioned segment of retina to the right of the picture. On traversing the substance of the lesion (dashed line) regrowing axons have a disordered pattern of growth (small arrow). Having emerged from the central aspect of the lesion, directed regrowth is re-established, with axons seen oriented towards the optic disc (large arrow). (B) At higher magnification, growth cones can be seen on these regrowing axons. Intraretinal axon guidance is therefore temporarily disrupted by the retinal scar, although on either side of the lesion the interaction with regenerating axons appears similar to that of normal development. In other similar experiments on lesioned adult retinae, axonal sprouting is totally random, suggesting that these intraretinal mechanisms of axon guidance do not operate at all on ganglion cells regenerating across a mature retina. Scale bars represent: (A) $250 \mu \mathrm{m}$, (B) $50 \mu m$.

grow directly through a retinal lesion, although the disordered growth observed at this point does suggest that the normal developmentally regulated signalling gradient is temporarily impaired (Fig. 1A). Beyond the lesion, however, axon growth is again centripetal and all growth cones become reoriented towards the optic disc (Fig. 1B).

Do these observations provide evidence that ganglion cells, although regenerating, still maintain the capacity to interact with normal intraretinal guidance cues either side of a retinal scar at early developmental stages? An alternative hypothesis might be that the correct orientation of regrowing axons within the lesioned retina is simply the result of passive fasciculation along the already-existing nerve fibre layer, especially since the orientation is apparently random on traversing disrupted neural tissue of the lesion site. This is a possibility, but similar anatomical features are also present in the lesioned adult retina, where there is a brief period of 
intraretinal axonal sprouting before ganglion cell death. In the adult model, however, ganglion cell growth is totally undirected, with axons found intermingled with deep retinal layers and oriented randomly with respect to the optic disc. ${ }^{25,26}$ Ganglion cells can also be encouraged to re-extend intraretinal growth cones when explants of peripheral nerve are inserted into the vitreous of the adult hamster. ${ }^{27}$ The orientation of these growth cones is similarly random and not even confined to the nerve fibre layer. Taken together, these results therefore imply that mechanisms of intraretinal axon guidance appear to be effective for regeneration only at early developmental stages.

In the adult, a far more ordered pattern of ganglion cell regeneration is seen if a peripheral nerve graft is connected to the retina after optic nerve transection. Thanos and $\mathrm{Mey}^{28}$ have shown that regenerating ganglion cells project directly towards and into a graft inserted at the optic nerve head, thus replicating the normal pattern of growth seen in development. So and colleagues, ${ }^{29}$ however, showed that axons also regenerate directly into ectopically placed grafts inserted some distance from the optic disc. Consequently the more centrally located ganglion cells regrow axons in a totally different direction to the normal orientation of the nerve fibre layer. Thus it is unlikely that regeneration into peripheral nerve grafts is directed by the normal developmental mechanisms of intraretinal axon guidance. Nevertheless, growth into the grafts is not random and some other process must be directing regenerating growth cones in these experiments. Fournier and McKerracher ${ }^{30,31}$ have shown that trophic factors released by peripheral nerve grafts may induce the expression in ganglion cells of tubulin, which is a vital cytoskeletal protein for axonal elongation. The apparently specific direction of regeneration towards grafts placed at the optic disc may therefore simply be the fortuitous result of facilitated growth along a gradient of exogenously released and non-specific trophic factors, rather than a specific axon guidance interaction within the retina.

\section{Axon guidance through the optic chiasm}

The mechanisms that guide normal development of the optic chiasm are only just beginning to be understood. ${ }^{32}$ The difficulty in applying these sketchy principles to regeneration is compounded by the absence, at present, of an adult model showing regeneration through the optic chiasm. This is unfortunate, as the clear ipsilateral or contralateral decussation choice taken by growth cones would provide an ideal point at which to investigate whether even this basic binary mechanism of axon guidance could be applied to regeneration. In the juvenile rat spinal cord, corticospinal axons have been reported to regenerate for distances greater than $7 \mathrm{~mm}$ in the presence of a growth factor (neurotrophin-3) and a hybridoma-derived antibody (IN-1) which neutralises the inhibitory effects of oligodendrocyte myelin. ${ }^{33}$ Applied to the rat optic nerve, this distance should be

\section{Optic chiasm}

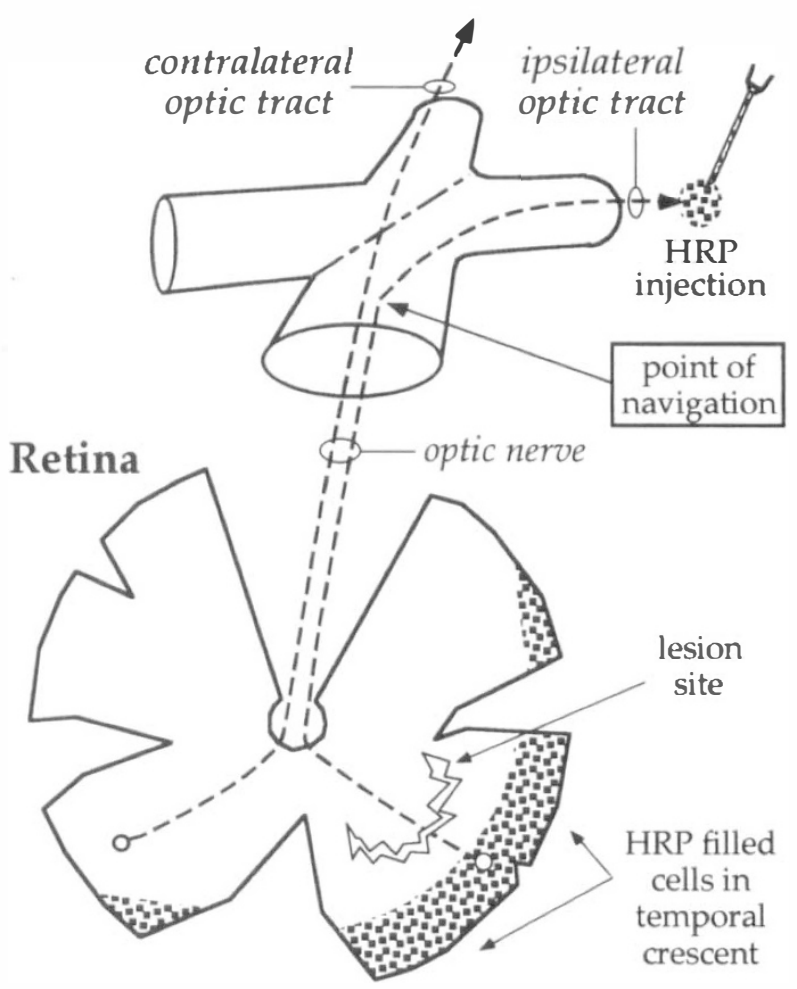

A

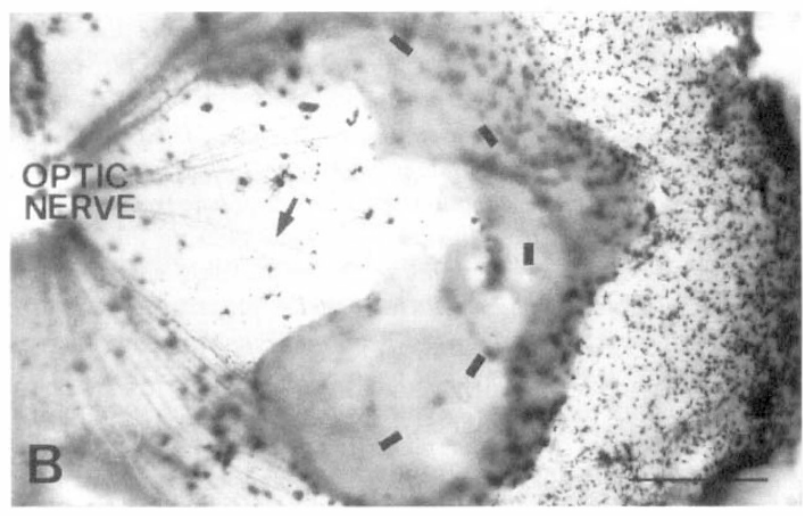

Fig. 2. Navigation of regenerating ganglion cells passing through the optic chiasm of the neonatal opossum. (A) Schematic diagram showing the course of axons arising from temporal retina: at the optic chiasm, an active point of navigation needs to operate in order to direct temporal axons into the ipsilateral optic tract. Retrograde labelling with horseradish peroxidase (HRP) from the ipsilateral tract will thus identify ganglion cells arising from the temporal retina capable of responding to this navigational interaction. (B) The presence of dense labelling beyond the retinal lesion suggests that chiasmatic navigation has been successful in addition to growth across scar tissue (dashed line). Axons are seen directed towards the optic disc (arrow). Doublelabelling experiments have confirmed that in the opossum about $40 \%$ of the normal projection is able to regenerate and successfully navigate into the ipsilateral optic tract when lesioned at P8. Scale bar represents $200 \mu \mathrm{m}$.

sufficient to allow regenerating growth cones to traverse the chiasm, but here comparable experiments combining an intraocular growth factor with myelin neutralisation have been of only limited success. The regenerating ganglion cells are few in number, of indeterminate retinal origin and do not extend as far as the optic chiasm. ${ }^{34}$ Regeneration across an optic nerve crush may also occur following intravitreal implantation of trophic factors 

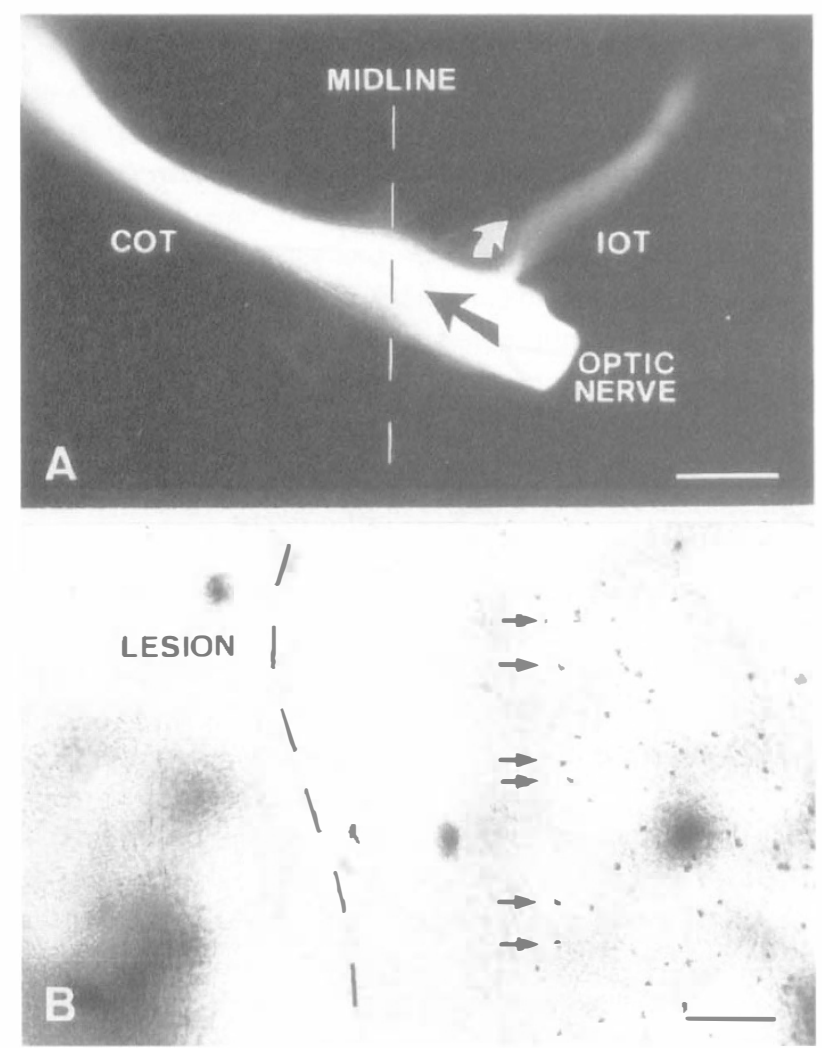

Fig. 3. Specificity of chiasmatic navigation by regenerating ganglion cells. (A) Anterograde tracing from a large DiI implant located behind a lesion made at P8 in the temporal retina. Some axons are directed by a specific navigational interaction to enter the ipsilateral optic tract prior to meeting the uncrossed projection from the fellow eye (white arrow); the main body of axons continues along the 'default pathway' to form the contralateral projection (black arrow). COT, contralateral optic tract; IOT, ipsilateral optic tract. (B) Retrograde tracing with horseradish peroxidase from the ipsilateral optic tract. In this case the P8 lesion was made more centrally in the retina. Only the more peripherally located ganglion cells turn at the optic chiasm; the remainder form the normal crossed pathway. Thus entry into the ipsilateral optic tract is dependent upon retinal location. Taken in conjunction with the retrograde tracing experiments described in Fig. 2 , this is evidence of chiasmatic specificity (and thus active navigation) for ganglion cells regenerating early in development. The extent to which this navigational interaction might operate in the adult chiasm is presently unknown. Scale bars represent: (A) $500 \mu \mathrm{m}$; (B) $50 \mu \mathrm{m}$.

derived from peripheral nerves, but the very small number of axons extending towards the optic chiasm has also made the assessment of any decussation pattern virtually impossible. ${ }^{5}$

Interpretation of the results from regeneration along peripheral nerve grafts poses alternative problems. The glial elements of the chiasmatic midline in rodents ${ }^{35,36}$ or prechiasmatic region in marsupials ${ }^{18}$ appear to be important for the segregation and decussation that occurs during normal development of the retinotectal projection. It is therefore difficult to understand how decussation might occur during regeneration along peripheral nerve grafts, which bypass this region altogether in order to lead regenerating neurons directly onto tectal targets. ${ }^{7,37}$ Wizenmann and colleagues ${ }^{38}$ have shown with in vitro experiments that basic nasotemporal guidance molecules reappear on the adult rat superior colliculus about 12 days after deafferentation. When cultured, preferential growth of ganglion cells from nasal or temporal retina is seen on either posterior or anterior superior colliculus respectively. ${ }^{38}$ Thus the adult deafferented tectum seems capable of re-expressing molecules that might interact and recognise axons regenerating from either the ipsilateral or contralateral retinofugal projections. However, when axons regenerate along peripheral nerve grafts connected directly to the ipsilateral tectum in vivo, both temporal and nasal retina appear to be able to make connections. ${ }^{28}$ The termination of both temporal and nasal axons on the ipsilateral tectum suggests that these molecules (if present) do not appear preferentially to recognise the normal uncrossed from crossed pathways following regeneration along a peripheral nerve graft.

Significant regeneration of the retinotectal projection directly through the optic chiasm has so far only been demonstrated very early in development in the opossum. ${ }^{20}$ This period is most favourable as myelin inhibitors to neurite growth are absent ${ }^{12}$ and sufficient developmentally regulated trophic molecules may still persist in the retina to propel regeneration. ${ }^{16}$ After lesioning the temporal retina up to P12 in the opossum, we found that axons were able to regrow through the optic nerve and chiasm and into the ipsilateral optic tract (Fig. 2). By counting regenerating ganglion cells labelled with tritiated thymidine and horseradish peroxidase, and comparing them with controls, we estimated that $40 \%$ of ganglion cells successfully regenerated into the ipsilateral projection when lesioned at $\mathrm{P} 8 .^{20}$ Although this figure only applies to ganglion cells lesioned at P8, it does provide strong evidence that the process of regeneration itself does not affect the ability of ganglion cells to navigate through the chiasm, at least during this favourable stage of development.

The important question to ask with this and other regeneration models is whether the presumed targeting observed is actually the result of active mechanisms of axon guidance, or whether it could be the result of interactions occurring by chance. In the case of chiasmatic navigation, for instance, passive fasciculation within the chiasm of the ipsilateral projection with contralaterally projecting axons from the fellow eye might indirectly lead axons regenerating from the temporal retina into the correct ipsilateral optic tract. Similarly the lesioned and degenerating ipsilateral pathway might leave a favourable physical 'channel' for regeneration. To investigate the question of targeting in more detail, we also employed anterograde labelling studies in order to trace precisely the path of axons regrowing from the lesioned temporal retina (Fig. 3A). These experiments revealed that the proportion of regrowing axons destined for the ipsilateral tract actually branch off from the main body of the optic nerve before meeting any axons from the fellow eye. This pattern replicates normal chiasm development and suggests that regenerating axons are also interacting with prechiasmatic recognition signals, most likely located in specialised glia of this region, ${ }^{18}$ rather than simply entering the ipsilateral tract 'by default'. Similarly, with lesions placed more centrally in the retina, the presence 
of a clear line of decussation across the lesioned segment of retina shows that only ganglion cells of the peripheral temporal retina are labelled from the ipsilateral tract. This suggests regeneration into the ipsilateral optic tract is indeed dependent upon retinal location (Fig. 3B), as the more centrally placed ganglion cells take an entirely contralateral course. ${ }^{19}$ If 'random' mechanisms were actually directing regeneration, some axons regenerating from the more centrally located ganglion cells might also have been expected to fellow the more peripheral axons into the ipsilateral optic tract.

Thus, early in development regenerating ganglion cells are able to navigate into the appropriate pathway, at least at the optic chiasm. This is perhaps not surprising, given that many guidance cues are operating in the immature CNS in order to direct navigation of newly forming projections. ${ }^{3}$ There is one issue, however, that may be of particular interest when considering axon guidance during regeneration. In these experiments, regenerating axons re-enter the chiasm at a more advance ontogenetic stage than normal, and would also most likely occupy a different position relative to other retinofugal axons when compared with normal development. ${ }^{39}$ This would also almost certainly be true if adult axons were ever successfully to regenerate along the normal retinofugal pathway. At these early stages at least, the presumed discrepancies in timing and location appear not to have a significant effect on regeneration targeting at the optic chiasm.

Following transplantation of embryonic retinae into diencephalic regions of neonatal mice, a basic form of decussation of axons emerging from the transplants may also be seen within the host brain. It is not clear how this relates to retinal topography, but this decussation also takes place at a later developmental stage than normal for the host. ${ }^{40}$ Although these axons are neogenic rather than regenerating, this might provide further evidence that axon guidance mechanisms driving chiasmatic segregation could persist longer than expected into adulthood.

\section{Selection of tectal targets}

In rodents approximately 5-20\% of retinal ganglion cells can reform long-term connections after regenerating through a peripheral nerve graft connected between the lesioned optic nerve head and tectum. ${ }^{28,41,42}$ Ganglion cells originating from throughout the retina may regenerate into a peripheral nerve graft $^{28,43}$ and it is therefore important to assess whether retinal topography might be re-established at centres of synapse formation.

Before interacting with mechanisms that guide tectal map formation, axons must first locate the tectum. With peripheral nerve transplant experiments, surgical apposition of the graft directly channels regenerating ganglion cell axons onto the tectum and therefore obviates a requirement for lengthy navigation towards this target. Indeed it is unclear whether there need be any target recognition at all, since ganglion cells are able to reform synapses in such diverse sites as the cerebellum if led there directly by a peripheral nerve graft. ${ }^{44}$ The observation that ganglion cells regenerating through a retinotectal peripheral nerve graft terminate in appropriate layers of the superior colliculus (stratum opticum and stratum griseum superficiale) has been presented by some workers as evidence of specific target recognition. ${ }^{41}$ Preferential growth along these layers, however, might simply be the result of facilitated reinnervation of deafferented sites in general, or preferential channelling of regenerating axons into the least myelinated layers. ${ }^{45}$ Specific target recognition is unlikely to occur in non-visual centres such as the cerebellum, yet even here retinal axons regenerating along grafts connected to this region also preferentially terminate in the least myelinated (granule cell) layer. ${ }^{44}$ These observations suggest that the apparent layerspecific termination of regenerating ganglion cells in the superior colliculus might simply be the result of the very non-specific property that growth cones tend to be repelled by oligodendrocytes and are therefore directed away from myelinated regions.

Axons emerging from retinal transplants in a host brain can also form fairly distant connections, but here the situation is somewhat different as these axons are neogenic and do not represent true regeneration. For specific target recognition, these developing neurons would also need to recognise molecular cues persisting in a host brain into adulthood. Transplantation experiments in neonatal mice have demonstrated some pathfinding properties for ganglion cell axons emerging from transplanted retinae: synapses are formed in appropriate visual centres, but sometimes via growth along highly anomalous routes. ${ }^{40}$ It is not clear whether this is random or because specific guidance molecules can persist beyond the normal embryonic period of retinofugal development. The anomalous routes taken by axons emerging from mesencephalic and diencephalic retinal transplant locations suggest that any signals that might be present are scattered widely within the host brain and do not specifically delineate the normal retinotectal pathway. In the adult rat brain, embryonic transplants can also form functional connections and even restore light reflexes, but these transplants need to be located very close to the pretectal nucleus. ${ }^{46}$ Whether the re-establishment of these reflexes is a result of specific target recognition or non-specific but fortuitous connection is therefore uncertain. In any case, there does not appear to be any evidence of a retinotopic map within the projections arising from embryonic retinal transplants. ${ }^{47}$

\section{Reformation of tectal maps}

The connection of a peripheral nerve graft between the lesioned optic nerve head and tectum presents an ideal opportunity to investigate whether an adult mammal might also be able to regenerate a retinal map within a central target. Long-distance navigation is largely irrelevant since the graft forms a direct conduit to the tectum. The issue is now whether significant re-ordering 


\section{Ipsilateral} Eye

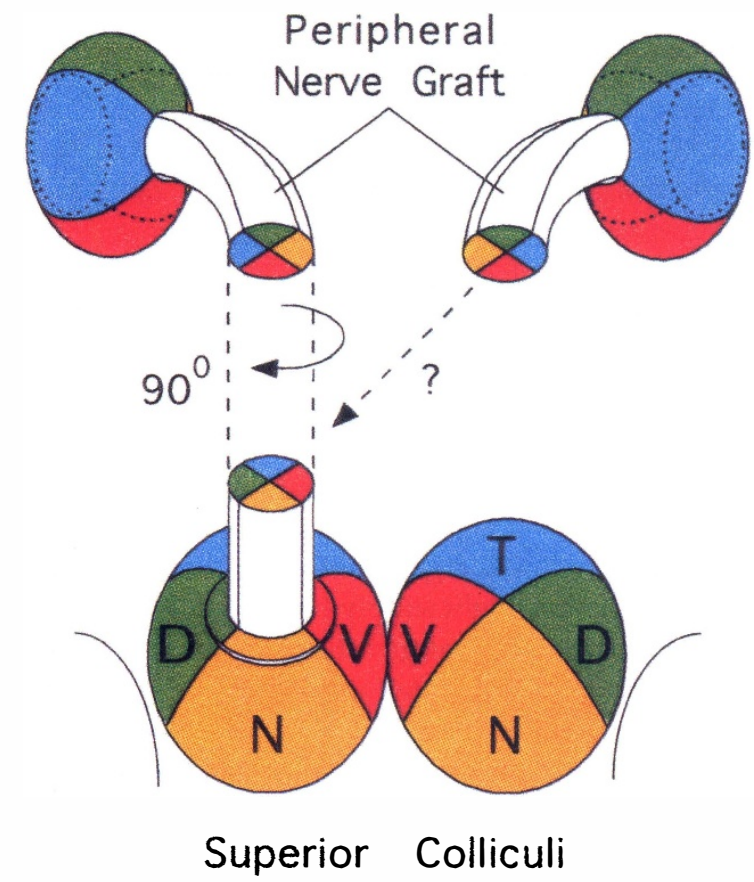

Fig. 4. Schematic diagram illustrating the maintenance of retinal topography along a peripheral nerve graft connected to the lesioned optic nerve head in an adult rodent. ${ }^{9}$ Without any active mechanisms of axon guidance, axons will be passively conducted along the graft, maintaining the basic topography of the optic nerve head. The normal intermingling of axons seen in the developing optic nerve is absent. The basic optic nerve head topography will thus be projected to any given point along the graft. Rotation of the peripheral nerve graft will therefore result in the emergence of a rotated, but nevertheless retinotopic, visual field on the optic tectum. With a $90^{\circ}$ anticlockwise rotation and appropriate positioning of an ipsilateral graft, the regenerated retinotopic map could fortuitously (but almost precisely) match the original map, although within a reduced terminal field. This precise mapping could never occur with a graft connected to the contralateral tectum: in this case a mirror reversal would also be required. The presence of a mirror reversal would imply an active reordering of the regenerating projection emerging from the graft and would therefore provide the strongest evidence of regeneration specificity. $N, T, D, V$ : normal mapping of nasal, temporal, dorsal and ventral retinal quadrants to the superior colliculus.

might also occur within the regenerated projection such that a retinotopic map could be recreated as axons emerge onto the tectal target. As discussed earlier, in vitro evidence suggests that nasotemporal recognition cues may be re-expressed on adult deafferented rat tectum. ${ }^{38,48}$ At the same time, astrocytes of the deafferented tectum re-express vimentin, ${ }^{49}$ which is a marker for the primitive radial glial cells of this region (radial glia may have an important role in axon guidance during development). ${ }^{32,39}$ This is a significant finding, but the cues for nasotemporal segregation may be different from the mechanisms of retinal map formation, since these occur as sequential and separate events in development. ${ }^{50,51}$ Also, during normal development of the retinotectal pathway a preliminary 'sorting out' of axons from dorsal and ventral retina first occurs within the optic tract. ${ }^{39}$ The optic tract is largely bypassed by a peripheral nerve graft and so this preliminary dorsoventral segregation is unlikely to occur within regenerating axons. Consequently when regenerating axons spill out of the graft onto the tectum, this basic dorsoventral map is missing. ${ }^{51}$ During normal development, aberrant and diffuse axonal projections ('arbors') are gradually retracted until a more precise map appears on the tectum. ${ }^{52}$ Without the initial dorsoventral targeting emerging from a graft connected to the tectum, the demands on the mechanisms of arbor refinement would therefore need to be considerably higher if a retinotopic map were to be recreated from a regenerated projection.

Recently Thanos and colleagues ${ }^{9}$ have provided evidence that adult rats with peripheral nerve grafts can differentiate between horizontal and vertical stripe patterns when 'seeing' the environment through a regenerated retinotectal projection. In these experiments, the graft was connected from the severed optic nerve head of one eye to the ipsilateral optic tectum. By inserting microscopic crystals of an axonally transported dye into different regions of the superior colliculus, and then identifying areas of retrograde fluorescence in a flattened retinal preparation, the authors could investigate how the regenerated projection mapped to the superior colliculus. Interestingly, they found that a basic (although in some cases rotated) retinotopic map had reformed within a reduced field of tectal innervation (Fig. 4). Furthermore, a basic map also existed at several points along the peripheral nerve graft. Is this evidence of navigation of regenerating ganglion cells?

Unfortunately, detailed analysis of these results leads one to conclude that quite the opposite might be true: the presence of a retinotopic map as the regenerating projection emerges from the peripheral nerve graft would be a predictable result in the absence of any active mechanisms of axon guidance. This is because a retinotopic map normally exists immediately behind the optic nerve head ${ }^{51}$ and will be projected into a graft connected at this point. A lack of any intermingling of axons (normally seen in the developing optic nerve as a result of active pathfinding by growth cones) might thus maintain this order throughout the length of the graft, as axons grow along pre-aligned tubes. At the point of contact with the tectum, innervation of adjacent deafferented regions of the superior colliculus will result in a reappearance of optic nerve head retinotopy. Rotation of the segment of peripheral nerve during surgical implantation would therefore also create a rotated map on the tectum. Interestingly, when grafting to ipsilateral colliculus, a $90^{\circ}$ anti-clockwise rotation could result in precise matching of the regenerated map (although reduced in size) to the original collicular map (Fig. 4). In any case, a rotation of the regenerated map is unlikely to affect the documented ability of rats with grafts to discriminate between horizontal and vertical stripe patterns: ${ }^{9}$ if $90^{\circ}$ out, for instance, what should be 
horizontal is actually perceived as vertical and vice versa, but the ability to differentiate between the two would remain.

For evidence of target specificity, retinal quadrants would need to regenerate to appropriate collicular quadrants, correcting any errors induced by peripheral nerve graft rotation. This would be comparable to the observations of successful optic nerve regeneration seen in amphibians, where rotation of the cut optic nerve results in a corrective re-rotation of the retinotectal projection during regeneration. ${ }^{53}$ This has not yet been shown in mammals. The connection of peripheral nerve grafts to the ipsilateral tectum is fortuitous, since a precise map could never occur without an active reordering following regeneration to the contralateral tectum. In the latter case a 'mirror reversal' ${ }^{54}$ would also be required in addition to $90^{\circ}$ rotation (Fig. 4). This would indeed be firm evidence of regeneration specificity.

\section{Conclusions}

In amphibians, regenerating ganglion cells are able to navigate specifically to tectal targets and reform a precise retinotopic map. In mammals a degree of ganglion cell regeneration is also possible under certain circumstances, but properties of navigation are only just beginning to be addressed. At very early developmental stages there is good evidence that regenerating ganglion cells are still able to interact with some of the normal developmental guidance cues that direct formation of the retinofugal pathway. Results from tissue culture experiments suggest that some of these axon guidance events could also theoretically occur in the adult, but to what extent this has been proven in the current experiments of adult in vivo regeneration is uncertain. Experiments showing tectal target recognition and retinal map reformation along peripheral nerve grafts could more easily be explained by fortuitous but non-specific properties of ganglion cell growth rather than an intrinsic mechanism of axon guidance. Further experiments with peripheral nerve grafts might prove whether or not a navigational interaction is also possible during regeneration of ganglion cells in the adult mammalian visual system.

I am very grateful to Jeremy Taylor for his advice and supervision of various aspects of this work and to Ray Guillery for critically reading the manuscript. I am also grateful to KwokFai So, Yutaka Fukuda and Masami Watanabe for their advice on technical aspects of optic nerve grafts. This work was supported by the Wellcome Trust and the Medical Research Council (UK).

\section{References}

1. Bähr M, Vanselow J, Thanos S. In vitro regeneration of adult rat ganglion cell axons from retinal explants. Exp Brain Res 1988;73:393-401.

2. Fukuda Y, Watanabe M, Sawai H, Miyoshi T. Functional recovery of vision in regenerated optic nerve fibers. Vision Res 1998;38:1545-53.
3. MacLaren RE, Taylor JSH. Regeneration in the developing optic nerve: correlating observations in the opossum to other mammalian systems. Prog Neurobiol 1997;53:381-98.

4. Fawcett JW, Rokos J, Bakst I. Oligodendrocytes repel axons and cause growth cone collapse. J Cell Sci 1989;92:93-100.

5. Berry M, Carlile J, Hunter A. Peripheral nerve explants grafted into the vitreous body of the eye promote the regeneration of retinal ganglion cell axons severed in the optic nerve. J Neurocytol 1996;25:147-70.

6. Thanos S. Adult retinofugal axons regenerating through peripheral nerve grafts can restore the light-induced pupilloconstriction reflex. Eur J Neurosci 1992;4:691-9.

7. Sawai H, Sugioka M, Morigiwa K, Sasaki H, So KF, Fukuda Y. Functional and morphological restoration of intracranial brachial lesion of the retinocollicular pathway by peripheral nerve autografts in adult hamsters. Exp Neurol 1996;137:94-104.

8. Kierstead SA, Rasminsky M, Fukuda Y, Carter DA, Aguayo AJ, Vidal-Sanz M. Electrophysiological responses in hamster superior colliculus evoked by regenerating retinal axons. Science 1989;246:255-7.

9. Thanos S, Naskar R, Heiduschka P. Regenerating ganglion cell axons in the adult rat establish retinofugal topography and restore visual function. Exp Brain Res 1997;114:483-91.

10. Sasaki H, Inoue T, Iso H, Fukuda Y, Hayashi Y. Light-dark discrimination after sciatic nerve transplantation to the sectioned optic nerve in adult hamsters. Vision Res 1993;33:877-80.

11. Varga ZM, Bandtlow CE, Erulkar SD, Schwab ME, Nicholls JG. The critical period for repair of CNS of neonatal opossum (Monodelphis domestica) in culture: correlation with development of glial cells, myelin and growth-inhibitory molecules. Eur J Neurosci 1995;7:2119-29.

12. MacLaren RE. Myelination in the opossum optic nerve: late appearance of inhibitors implicates an earlier non-myelin factor in preventing ganglion cell regeneration. J Comp Neurol 1996;372:27-36.

13. McKeon RJ, Schreiber RC, Rudge JS, Silver J. Reduction of neurite outgrowth in a model of glial scarring following CNS injury is correlated with the expression of inhibitory molecules on reactive astrocytes. J Neurosci 1991;11:3398-411.

14. MacLaren RE. Development and role of retinal glia in regeneration of ganglion cells following retinal injury. Br J Ophthalmol 1996;80:458-64.

15. Ernfors P, Merlio J, Persson H. Cells expressing mRNA for neurotrophins and their receptors during embryonic rat development. Eur J Neurosci 1992;4:1140-58.

16. Araujo EG, Linden R. Trophic factors produced by retinal cells increase the survival of retinal ganglion cells in vitro. Eur J Neurosci 1993;5:1181-8.

17. Wiebel D, Kreutzberg GW, Schwab ME. Brain-derived neurotrophic factor (BDNF) prevents lesion-induced axonal die-back in young rat optic nerve. Brain Res 1995;679:249-54.

18. Taylor JSH, Guillery RW. Early development of the optic chiasm in the Gray Short-Tailed Opossum, Monodelphis domestica. J Comp Neurol 1994;350:109-21.

19. MacLaren RE, Taylor JSH. A critical period for axon regrowth through a lesion in the developing mammalian retina. Eur J Neurosci 1995;10:2111-8.

20. MacLaren RE, Taylor JSH. Chiasmatic specificity in the regenerating mammalian optic nerve. Exp Neurol 1997;147:279-86.

21. Halfter $W$. Intraretinal grafting reveals growth requirements and guidance cues for optic axons in the developing avian retina. Dev Biol 1996;177:160-77.

22. Snow DM, Watanabe M, Letourneau PC, Silver J. A chondroitin sulfate proteoglycan may influence the direction of retinal ganglion cell outgrowth. Development 1991;113:1473-85. 
23. Brittis PA, Canning DR, Silver J. Chondroitin sulfate as a regulator of neuronal patterning in the retina. Science 1992;255:733-6.

24. Johnson AR. Contact inhibition in the failure of mammalian CNS axonal regeneration. BioEssays 1993;15:807-13.

25. Goldberg S, Frank B. Will central nervous systems in the adult mammal regenerate after bypassing a lesion? A study in the mouse and chick visual systems. Exp Neurol 1980;70:675-89.

26. McConnell P, Berry M. Regeneration of retinal ganglion cells in the adult mouse retina. Brain Res 1982;241:362-5.

27. Cho EYP, So KF. Characterization of the sprouting response of axon-like processes from retinal ganglion cells after axotomy in adult hamsters: a model using intravitreal implantation of a peripheral nerve. J Neurocytol 1992;21:589-603.

28. Thonas S, Mey J. Type-specific stabilization and targetdependent survival of regenerating ganglion cells in the retina of adult rats. J Neurosci 1995;15:1057-79.

29. So KF, Xiao YM, Diao YC. Effects on the growth of damaged ganglion cell axons after peripheral nerve transplantation in adult hamsters. Brain Res 1986;377:168-72.

30. Fournier AE, McKerracher L. Expression of specific tubulin isotypes increases during regeneration of injured CNS neurons, but not after the application of brain-derived neurotrophic factor (BDNF). J Neurosci 1997;17:4623-32.

31. Fournier AE, McKerracher L. Tubulin expression and axonal transport in injured and regenerating neurons on the adult mammalian central nervous system. Biochem Cell Biol 1995;73:659-64.

32. Guillery RW, Mason CA, Taylor JSH. Developmental determinants at the mammalian optic chiasm. J Neurosci 1995;15:4727-37.

33. Schnell L, Schneider R, Kolbeck R, Barde YA, Schwab ME. Neurotrophin-3 enhances sprouting of corticospinal tract during development and after adult spinal cord lesion. Nature 1994;367:170-3.

34. Wiebel D, Cadelli D, Schwab ME. Regeneration of lesioned rat optic nerve fibers is improved after neutralization of myelin-associated growth inhibitors. Brain Res 1994;642:259-66.

35. Sretavan DW, Pure E, Siegel MW, Reichardt LF. Disruption of retinal axon ingrowth by ablation of embryonic mouse optic chiasm neurons. Science 1995;269:98-101.

36. Marcus RC, Blazeski R, Godement P, Mason CA. Retinal axon divergence in the optic chiasm: uncrossed axons diverge from crossed axons within a midline glial specialization. J Neurosci 1995;15:3716-29.

37. Aguayo AJ. Regrowth and reconnection of severed axons in the visual system of adult mammals. In: Lam DM, Bray GM, editors. Regeneration and plasticity in the mammalian visual system. Cambridge: MIT Press, 1992:233-40.
38. Wizenmann A, Thies E, Klostermann S, Bonhoeffer F, Bähr $M$. Appearance of target-specific guidance information for regenerating axons after CNS lesions. Neuron 1993;11:975-83.

39. Guillery RW. Development of the pathways from the eye to the optic tract. In: Lam DM, Shatz CJ, editors. Development of the visual system. Boston: MIT Press, 1991:153-71.

40. Lund RD, Hankin MH. Pathfinding by retinal ganglion cell axons: transplantation studies in genetically and surgically blind mice. J Comp Neurol 1995;356:481-9.

41. Carter DA, Bray GM, Aguayo AJ. Long-term growth and remodelling of regenerated retino-collicular connections in adult hamsters. J Neurosci 1994;14:590-8.

42. Villegas-Pérez MP, Vidal-Sanz M, Bray G, Aguayo AJ. Influences of peripheral nerve grafts on the survival and regrowth of axotomized retinal ganglion cells in adult rats. J Neurosci 1988;8:265-80.

43. Watanabe M, Sawai H, Fukuda Y. Number, distribution, and morphology of retinal ganglion cells with axons regenerated into peripheral nerve graft in adult cats. J Neurosci 1993;13:2105-17.

44. Zwimpfer TJ, Aguayo AJ, Bray GM. Synapse formation and preferential distribution in the granule cell layer by regenerating retinal ganglion cell axons guided to the cerebellum of adult hamsters. J Neurosci 1992;12:1144-59.

45. Schwab ME, Schnell L. Channeling of developing rat corticospinal axons by myelin-associated neurite growth inhibitors. J Neurosci 1991;11:709-21.

46. Klassen H, Lund RD. Retinal graft-mediated pupillary responses in rats: restoration of a reflex function in the mature mammalian brain. J Neurosci 1990;10:578-87.

47. Galli L, Rao K, Lund RD. Transplanted rat retinae do not project in a topographic fashion on the host tectum. Exp Brain Res 1989;74:427-30.

48. Wizenmann A, Bähr M. Growth characteristics of ganglion cell axons in the developing and regenerating retino-tectal projection of the rat. Cell Tissue Res 1997;290:395-403.

49. Wilms P, Bähr M. Reactive changes in the adult rat superior colliculus after deafferentation. Rest Neurol Neurosci 1995;9:21-34.

50. Jhaveri S, Edwards MA, Schneider GE. Initial stages of retinofugal axon development in the hamster: evidence for two distinct modes of growth. Exp Brain Res 1991;87:371-82.

51. Simon DK, O'Leary DM. Relationship of retinotopic ordering of axons in the optic pathway to the formation of visual maps in central targets. J Comp Neurol 1991;307:393-404.

52. Fujisawa H, Tani N, Watanabe K, Ibata Y. Branching of regenerating retinal axons and preferential selection of appropriate branches for specific neuronal connection in the newt. Dev Biol 1982;90:43-57.

53. Sperry RW. Optic nerve regeneration with return of vision in anurans. J Neurophysiol 1944;7:57-69.

54. Adams NC, Lozsádi DA, Guillery RW. Complexities in the thalamocortical and corticothalamic pathways. Eur J Neurosci 1997:9:204-9. 